\title{
Iron but not folic acid supplementation reduces the risk of low birthweight in pregnant women without anaemia: a case-control study
}

\author{
S Palma, ${ }^{1}$ R Perez-Iglesias, ${ }^{2}$ D Prieto, ${ }^{2}$ R Pardo, ${ }^{2} \mathrm{~J}$ Llorca, ${ }^{2}$ M Delgado-Rodriguez ${ }^{1,2}$
}

${ }^{1}$ Division of Preventive Medicine and Public Health, University of Jaen, Jaen, Spain; ${ }^{2}$ Division of Preventive Medicine and Public Health, University of Cantabria, Santander, Spain

Correspondence to: Dr M Delgado-Rodriguez, Division of Preventive Medicine and Public Health, University of Jaen, 23071 Jaen, Spain: mdelgado@ujaen.es

Accepted 28 March 2007

\section{ABSTRACT}

Objective: To assess whether iron and folic acid supplementation reduce the risk of low birthweight (LBW) in women without anaemia.

Design: Case-control study.

Setting: University Hospital of Cantabria.

Study population: Cases were 322 mothers without anaemia delivering a singleton infant of less than $2500 \mathrm{~g}$. Controls were 934 mothers without anaemia delivering a term non-small-for-gestational-age infant.

Data collection: Data on iron and folic acid supplementation were obtained from prenatal chart record and personal interview. Data on risk factors for LBW were also gathered.

Results: Agreement between the two sources of information was good (82\% for folic acid and 94\% for iron). Odds ratios yielded from the two sources were very close. Folic acid only (15 mg/day) was unrelated to LBW, whereas iron supplementation (80 mg ferrous sulphate) was associated with a lower risk of LBW (odds ratio (OR) $0.58,95 \% \mathrm{Cl} 0.34$ to 0.98 ), adjusted for smoking, maternal education, body mass index, obstetric diseases during pregnancy, weight gain during pregnancy, and previous LBW. The results of iron plus folic acid were similar to those for iron (OR 0.56, 95\% Cl 0.33 to 0.96). There was a significant trend towards a lower risk of LBW $(p<0.001)$ with the duration of iron supplementation. After stratifying by the type of LBW, the trend was also significant for any kind of LBW.

Conclusions: Iron supplementation is associated with a lower risk of LBW in pregnant women without anaemia.

Current knowledge indicates that anaemia in pregnancy is a risk factor for preterm delivery and subsequent low birthweight (LBW). ${ }^{12}$ The US Preventive Services Task Force in 1996 concluded that there was currently insufficient evidence to recommend for or against the routine use of iron supplements for healthy pregnant women, ${ }^{3}$ and this statement has not changed since then. ${ }^{4}$ Nevertheless, routine iron and folic acid supplementation is recommended during pregnancy to avoid the deleterious effect of anaemia on birthweight. ${ }^{2}$ Not all women in developed countries receive iron supplementation..$^{5-8}$ It has been suggested that a selective supplementation reserved for women with anaemia should be preferred to routine supplementation because iron is a potentially toxic element and unjustified supplementation could expose women to high levels of iron and to oxidative stress, which is also observed in pregnancy pathologies (preeclampsia, gestational diabetes). ${ }^{9}$
Two clinical trials in pregnant women without anaemia in developed countries have been reported. The first was performed on 275 lowincome women from Cleveland, Ohio, United States, for whom data on birthweight were available for 213 women; the study reported a fourfold lower incidence of LBW (from 17\% to 4\%) in the treatment arm, $30 \mathrm{mg}$ iron for approximately 10 weeks. ${ }^{10}$ The second trial, reported in 2006, randomly assigned US women eligible for the Special Supplemental Nutrition Program for Women, Infants and Children, into four arms in 1997-1999. ${ }^{11}$ Two arms were women without anaemia, 218 were assigned to receive iron (30 mg) and 211 were assigned to placebo. Data were reported on the outcomes of 166 and 168 women of the treatment and placebo arms, respectively. The frequency of several outcomes in the treatment and placebo groups were as follows: LBW $4.8 \%$ versus $9.5 \%(p=0.09)$; small for gestational age (SGA) 10.8 versus $15.5 \%$ $(p=0.22)$; and preterm delivery $7.5 \%$ versus 13.9 $(p=0.05)$. Despite these results, there are doubts about the benefits of iron supplementation and therefore it is not fully endorsed. ${ }^{12}{ }^{13}$ Currently available evidence is thus insufficient to support or reject this practice for the specific purposes of raising birthweight. ${ }^{14}$

Observational studies provide a lower evidence level than trials, although they can be useful in evaluating programmes in the field. We present the results of a case-control study to assess whether iron and folic supplementation among pregnant women without anaemia is associated with LBW.

\section{METHODS}

The study population includes women seen at the University of Cantabria Hospital (Spain), a nonprofit 1200-bed referral centre serving 525000 people (the entire region of Cantabria, northern Spain). Case and control groups were collected from 1 April 1998 to 30 November 2002. The Ethics Committee of the hospital authorised the study. Oral informed consent was sought from every eligible woman.

Eligibility criteria for cases were the delivery of a single live infant weighing less than $2500 \mathrm{~g}$ without congenital malformations during the study period, residence in the referral area of the hospital, receiving prenatal care (first visit in the first trimester and at least five visits during pregnancy), and without anaemia during pregnancy (anaemia was defined as a haemoglobin level less than $11 \mathrm{~g} / 1$ regardless of gestational age). No woman declined 
Table 1 Description of the study population according to sociodemographic characteristics (age, education, primiparity), characteristics of the infant (weight, gestational age) and risk factors for low birthweight (smoking, body mass index, weight gain per week during pregnancy)

\begin{tabular}{|c|c|c|c|}
\hline Variable & $\begin{array}{l}\text { Cases } \\
(n=322)\end{array}$ & $\begin{array}{l}\text { Controls } \\
(n=934)\end{array}$ & $\mathbf{p}$ \\
\hline \multicolumn{4}{|l|}{ Maternal age, years, \% } \\
\hline$\leqslant 20$ & 4.0 & 4.1 & \\
\hline $21-35$ & 81.4 & 85.3 & \\
\hline$>35$ & 14.6 & 10.6 & 0.154 \\
\hline \multicolumn{4}{|l|}{ Maternal education, \% } \\
\hline$\leqslant$ Primary school & 20.5 & 23.2 & \\
\hline Secondary & 71.7 & 66.0 & \\
\hline University & 7.8 & 10.8 & 0.122 \\
\hline Primigravidae, $\%$ & 48.5 & 45.5 & 0.361 \\
\hline \multicolumn{4}{|l|}{ Smoking in pregnancy, \% } \\
\hline No & 56.5 & 67.0 & \\
\hline $1-10$ cigarettes/day & 33.5 & 27.6 & \\
\hline$>10$ cigarettes/day & 10.0 & 5.4 & $<0.001$ \\
\hline Body mass index (SEM), $\mathrm{kg} / \mathrm{m}^{2}$ & $23.2(0.2)$ & $23.7(0.1)$ & 0.031 \\
\hline Weight gain per week during pregnancy (SEM), g & $255(6)$ & $296(3)$ & $<0.001$ \\
\hline Weight of infant (SEM), g & $2041(25)$ & $3340(14)$ & $<0.001$ \\
\hline Gestational age (SEM), days & $250(1)$ & $277(1)$ & $<0.001$ \\
\hline
\end{tabular}

to participate. A total of 322 cases were included; 187 were preterm and 108 were SGA.

The selection of controls was as follows. A random sample of one sixth of all women delivering at the hospital was drawn by using the following procedure: each month for the study period, all women delivering on five days, randomly selected in advance, were asked to participate $(n=1550)$. Forty-nine women had already been identified and included in the group of cases or they had a preterm or SGA infant, 11 women had infants with congenital malformations, 28 women declined participation, 528 did not receive adequate prenatal care (as defined for cases) and information on anaemia status was lacking, leaving 934 women in the control group.

Three sources of data were used: personal interviews (carried out within the three days after delivery), clinical charts, and prenatal care records. Information was obtained on the following variables: mother's vital data (age at pregnancy, race, education level, marital status, socioeconomic class, and occupation, from interview), obstetric history (parity and abortions, from the prenatal care record), previous adverse perinatal outcomes, conditions during pregnancy (infections, preeclampsia, diabetes, and other obstetric conditions from the prenatal care record), birthweight (weight in grams in the delivery room), prescribed and over-the-counter drugs (from both prenatal care record and from interview), smoking during pregnancy (interview), and prenatal care (number of visits and date of first visit, from prenatal care record and interview in those receiving private care). Social class was coded in five main levels (ranging from I, the highest, to V, the lowest) according to the classification of the Spanish Society of Epidemiology, ${ }^{15}$ which is close to that of the Black Report. ${ }^{16}$ Information on iron and folic supplementation and other supplements was obtained from two sources: personal interview and prenatal care record. Data on the duration of intake were obtained by personal interview (this information was not included in the prenatal care record) after asking for the date of pregnancy when intake began and the date of pregnancy when medication was stopped. A woman was included in the group "taking supplements" if the duration of intake lasted at least one week.

Comparison of proportions was assessed by the Fisher's exact test and the $t$-test was applied to compare means. The

Table 2 Association between folic acid, iron supplementation and risk of low birthweight using two sources of information (prenatal care record and maternal interview)

\begin{tabular}{|c|c|c|c|c|}
\hline & Cases & Controls & $\begin{array}{l}\text { Crude OR } \\
\text { (95\% CI) }\end{array}$ & $\begin{array}{l}\text { Adjusted OR* } \\
\text { (95\% CI) }\end{array}$ \\
\hline \multicolumn{5}{|c|}{ From prenatal care record } \\
\hline No. & 24 & 44 & 1 (ref.) & 1 (ref.) \\
\hline Folic acid only & 11 & 16 & $1.26(0.45$ to 3.44$)$ & 1.31 (0.50 to 3.42$)$ \\
\hline Iron only & 82 & 248 & 0.61 (0.34 to 1.11$)$ & $0.59(0.33$ to 1.07$)$ \\
\hline Folic acid plus iron & 120 & 365 & $0.60(0.34$ to 1.08$)$ & 0.55 (0.31 to 0.96$)$ \\
\hline NA & 85 & 261 & & \\
\hline \multicolumn{5}{|l|}{ From maternal interview } \\
\hline No. & 27 & 54 & 1 (ref.) & 1 (ref.) \\
\hline Folic acid only & 14 & 17 & $1.65(0.64$ to 4.16$)$ & 1.43 (0.59 to 3.47$)$ \\
\hline Iron only & 145 & 452 & $0.64(0.38$ to 1.10$)$ & 0.58 (0.34 to 0.98$)$ \\
\hline Folic acid plus iron & 134 & 407 & $0.66(0.39$ to 1.13$)$ & $0.56(0.33$ to 0.96$)$ \\
\hline NA & 2 & 4 & & \\
\hline
\end{tabular}

NA, Not available; OR, odds ratio.

Crude and multiple risk factor-adjusted for (logistic regression) analyses.

${ }^{*}$ Adjusted for smoking, maternal education, maternal age, Kessner index, body mass index, obstetric diseases during pregnancy, gestational age, and weight gain during pregnancy. 
Table 3 Duration of folic acid and iron supplementation and risk of low birthweight using the information from maternal interview

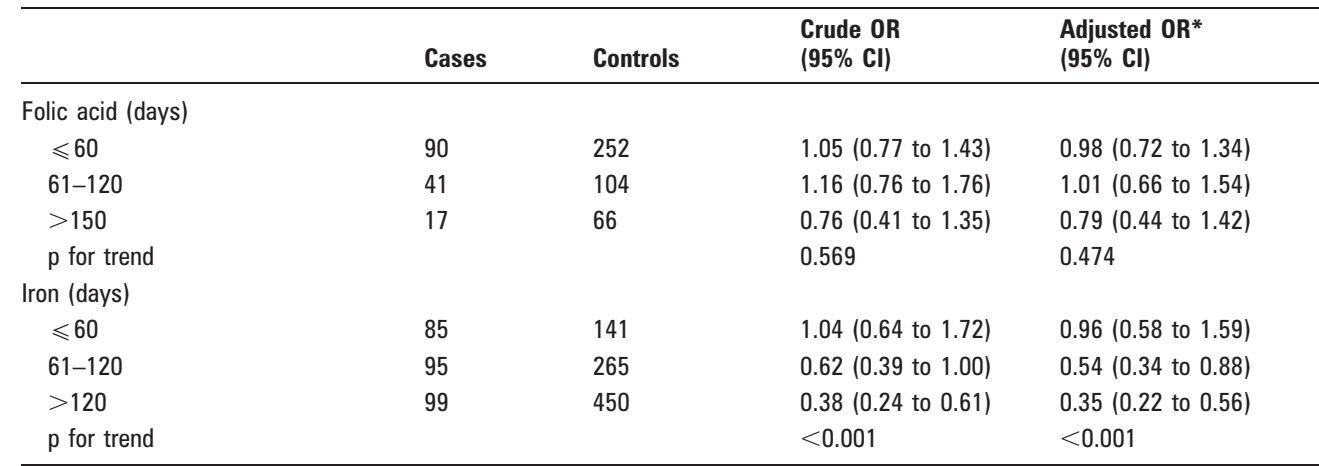

NA, Not available; $O R$, odds ratio.

Crude and multiple risk factor-adjusted for (logistic regression) analyses.

${ }^{*}$ Adjusted for smoking, maternal education, maternal age, Kessner index, body mass index, obstetric diseases during pregnancy, gestational age, and weight gain during pregnancy.

agreement between the data provided by the two sources of iron and folic supplementation was assessed by the kappa statistic. Associations between the supplements (from the two sources) and LBW were assessed by odds ratio (OR) and its $95 \%$ confidence interval (CI). Multiple risk factor-adjusted OR were estimated by means of logistic regression. To determine variables to be included in multivariate logistic regression analysis, the procedure described by Sun et al. ${ }^{17}$ was followed. Intermediate variables were discarded. Two stepwise models were run, one backward and another forward, allowing the entry of variables with $p<0.2 .^{18}{ }^{19} \mathrm{We}$ made a list of predictors of LBW identified in other studies. With information from stepwise models and the list of predictors, a saturated model was built, and by using a heuristic approach, variables that did not change the coefficient of birthweight by more than $10 \%$ were discarded. ${ }^{18}$ The objective was to have a parsimonious model retaining all important confounders. All analyses were repeated, stratifying by gestational age (preterm and term LBW) and SGA (yes/no). If substantial differences were found, they are mentioned as footnotes in tables and noted in the text. The Stata 8.0-SE statistical package (Stata Corp., College Station, Texas, USA) was used in analyses.

\section{RESULTS}

Characteristics of the study population are listed in table 1. Cases and controls do not differ significantly with regard to maternal age and education. Smoking was more frequent in cases. Controls had a higher body mass index and weight gain during pregnancy. Agreement between the information from personal interview and prenatal care record was high, $82.1 \%$ for folic acid and $93.6 \%$ for iron. Kappa statistics were 0.64 (SEM 0.03 ) for folic acid and 0.55 (SEM 0.03) for iron supplementation.

All women reporting folic acid supplementation took one of the following two drugs (single supplement): pills of folic acid $5 \mathrm{mg} /$ three times a day or one pill a day of folinic acid $15 \mathrm{mg}$. Some $91.8 \%(256 / 279)$ of the cases and $93.0 \%$ (799/859) of controls taking iron supplementation took one pill a day (single supplement) of ferrous sulphate $80 \mathrm{mg}$.

As folic acid and iron are commonly used simultaneously, the independent association of each supplementation was assessed separately (table 2). The results with both sources of information, interview and prenatal care chart, were similar. Women taking folic acid only did not show any relationship with LBW. The strength of the association between iron only and LBW was similar to that obtained with folic acid plus iron (very close OR) and approximately halved the risk of LBW.

The relationship between the duration of use of the supplements and the risk of LBW is shown in table 3. Folic acid was unrelated to the risk of LBW. Stratified analyses by type of LBW (either preterm or term, SGA or non-SGA) gave similar results (data not shown). There was also a decreasing trend of LBW risk with the increasing length of iron supplementation $(\mathrm{p}<0.001)$. This trend was also statistically significant for all categories of LBW; a duration longer than four months of supplementation gave significant protective OR for term LBW (OR 0.40, 95\% CI 0.20 to 0.81), preterm LBW (OR $0.27,95 \%$ CI 0.15 to 0.49 ), SGA (OR $0.43,95 \%$ CI 0.20 to 0.90 ) and non-SGA (OR 0.31, 95\% CI 0.18 to 0.53 ).

Finally, we assessed whether iron supplementation was associated with preeclampsia and gestational diabetes (table 4).

Table 4 Association of iron supplementation with preeclampsia and gestational diabetes in both groups (cases and controls) separately

\begin{tabular}{|c|c|c|c|c|c|c|}
\hline \multirow[b]{3}{*}{ Condition } & \multicolumn{3}{|l|}{ Controls } & \multicolumn{3}{|l|}{ Cases } \\
\hline & \multicolumn{2}{|c|}{ Iron supplementation } & \multirow[b]{2}{*}{ p Value } & \multicolumn{2}{|c|}{ Iron supplementation } & \multirow[b]{2}{*}{ p Value } \\
\hline & Yes n (\%) & No n (\%) & & Yes n (\%) & No n (\%) & \\
\hline \multicolumn{7}{|c|}{ Preeclampsia } \\
\hline Yes & $29(3.4)$ & $7(9.9)$ & 0.016 & 48 (17.2) & $14(34.2)$ & 0.018 \\
\hline No & $830(96.6)$ & $64(90.1)$ & & $231(82.8)$ & $27(65.9)$ & \\
\hline \multicolumn{7}{|c|}{ Gestational diabetes } \\
\hline Yes & $36(4.2)$ & $5(7.0)$ & 0.233 & $17(6.1)$ & $3(7.3)$ & 0.730 \\
\hline No & $823(95.8)$ & $66(93.0)$ & & 262 (93.9) & $38(92.7)$ & \\
\hline
\end{tabular}

Information was missed in two cases and four controls. 
As this is a case-control study, associations were ascertained in cases and controls separately. No difference was found in gestational diabetes; the frequency was similar with and without iron supplementation in both cases and controls. Preeclampsia was, however, significantly less frequent in women taking iron supplementation in both cases and controls.

\section{DISCUSSION}

Our results suggest that iron but not folic acid supplementation in women without anaemia is associated with a lower risk of LBW without increasing other adverse conditions. These results come from an observational study and they may suffer from a higher likelihood of bias than clinical trials. A potential drawback is recall bias. It is unlikely that this bias could explain our results as information from prenatal maternal chart yielded similar results to that from maternal interview. One advantage of observational studies is that they provide data on the effectiveness of an intervention under actual conditions.

The benefits of iron supplementation in pregnant women have been studied in several trials. In three trials iron supplementation was compared with placebo and no distinction between anaemia and non-anaemia during pregnancy was made. In an Indian trial, it reduced the incidence of $\mathrm{LBW},{ }^{20}$ whereas in an American trial it increased birthweight and reduced preterm delivery but not SGA. ${ }^{11}$ In a third trial in Wisconsin (USA) on women with prepregnancy normal iron stores, however, no significant differences were seen in maternal or neonatal health, although the number of women was small. ${ }^{21}$

Concerns have been raised about the potential disadvantages of giving iron supplementation to women without anaemia. ${ }^{8}$ There have been two American trials on low-income women without anaemia. In the Cleveland trial women receiving a dose of $30 \mathrm{mg}$ per day had a fourfold reduction (from 17\% to $4 \%$ ) in the risk of LBW, mainly preterm LBW; ${ }^{10}$ however, the study was not powered to detect any influence on SGA. In the Raleigh trial, ${ }^{11}$ the risk of LBW in the treatment group was halved, although the figure was not significant $(p=0.09)$. These results agree with ours. There is also evidence from a case-control study on all pregnant women (with and without anaemia) that iron supplementation prevents SGA. ${ }^{22}$

Regarding the association between folic acid and birthweight, a systematic review published in $1997,{ }^{23}$ combining five trials (with 447 treated women versus 438 placebo), suggested that folic acid decreases term LBW (OR 0.60, 95\% CI 0.37 to 0.97 ); most of the trials included in the review defined their populations poorly, did not give details of randomisation procedures, and did not take iron supplementation into account, although it was routine. It has been found that serum folate concentrations showed negative relationships with the incidence of foetal growth retardation as well as the birthweight of infants, ${ }^{24-26}$ although a previous study had shown that anaemia other than iron deficiency was unrelated to LBW and preterm delivery. ${ }^{1}$ In New Zealand, a case-control study of SGA folic acid supplementation also showed a reduced risk. ${ }^{22}$ In a Danish trial the effects of supplementing the diet with folic acid given preconceptionally or in the first half of pregnancy were a slight increase of birthweight and a decrease in the incidence of preterm labour, LBW and SGA; the greatest effect was seen in the groups receiving folic acid preconceptionally. ${ }^{27}$ Other trials have, however, failed to show any advantage of folic acid supplementation on birthweight. ${ }^{28} 29$

We have not reported the effect of supplementing other micronutrients on LBW. The number of women using these supplements was small (16 cases and 66 controls). The available

\section{What this paper adds}

Iron supplementation is associated with a lower risk of LBW in pregnant women without anaemia without increasing preeclampsia or gestational diabetes

\section{Policy implications}

The results suggest that a small-dose iron supplementation should be recommended to all pregnant women

trials have reported conflicting results. Two trials carried out in developing countries and comparing multiple micronutrient supplementation with folic acid plus iron have shown a decreased LBW in women with anaemia only ${ }^{30}$ and an increase in birthweight. ${ }^{31}$ Another trial showed a slight beneficial effect, although the results did not achieve statistical significance. ${ }^{32}$ Finally, another trial on semirural women in Mexico did not report a greater advantage over iron-only supplementation. ${ }^{33} \mathrm{~A}$ Cochrane review found that multiple micronutrient supplementations were not better than folic acid plus iron supplements. $^{34}$

Our results suggest that iron but not folic acid supplementation in women without anaemia is associated with a lower risk of LBW. The main goal of iron supplementation is to avoid iron deficiency, which could cause LBW by several mechanisms. ${ }^{35}$ There is, however, a danger of adverse effects if iron is supplemented above the needs of pregnancy. ${ }^{8}$ Much of the information on the benefits of supplementation come from studies carried out in developing countries where malnutrition is common. Two trials on women without anaemia have recently been reported in the developed world showing the benefits of iron supplementation, one with data on 213 women ${ }^{10}$ and the other on 334 women $^{11}$. Observational studies, such as ours, can provide useful information while waiting for a larger trial with enough statistical power to detect all the benefits and adverse effects in women without anaemia.

Funding: This work was funded by the Andalusian Regional Ministry of Education and Science (CTS 435) and a grant from the Foundation Marques de Valdecilla (University of Cantabria).

Competing interests: None.

\section{REFERENCES}

1. Scholl TO, Hediger ML, Fischer RL, et al. Anemia vs iron deficiency: increased risk of preterm delivery in a prospective study. Am J Clin Nutr 1992;55:985-8.

2. Allen LH. Anemia and iron deficiency: effects on pregnancy outcome. Am J Clin Nutr 2000; 11 (Suppl):1280S-4.

3. US Preventive Services Task Force. Guide to clinical preventive services: an assessment of the effectiveness of 169 interventions, 2nd ed. Baltimore: Williams and Wilkins, 1996:231-46.

4. US Preventive Services Task Force. Guide to clinical preventive services. http:// www.ahrq.gov/clinic/uspstfix.htm\#Active (accessed 25 Aug 2006)

5. Mungen E. Iron supplementation in pregnancy. J Perinat Med 2003;31:420-6.

6. Offerhaus $\mathbf{P}$, Fleuren $\mathrm{M}$, Wensing $\mathbf{M}$. Guidelines on anaemia: effect on primary-care midwives in The Netherlands. Midwifery 2005;21:204-11.

7. Wulff M, Ekstrom EC. Iron supplementation during pregnancy in Sweden: to what extent is the national recommendation followed? Acta Obstet Gynecol Scand 2003;82:628-35.

8. Nordeng $\mathbf{H}$, Eskild A, Nesheim Bl, et al. Guidelines for iron supplementation in pregnancy: compliance among 431 parous Scandinavian women. Eur J Clin Pharmacol 2003;59:163-8.

9. Favier $\mathbf{M}$, Hininger-Favier I. Faut-il supplémenter en fer les femmes enceintes? Gynecol Obstet Fertil 2004;32:245-50. 
10. Cogswell ME, Parvanta I, Ickes L, et al. Iron supplementation during pregnancy, anemia, and birth weight: a randomized controlled trial. Am J Clin Nutr 2003;78:77381.

11. Siega-Riz AM, Hartzema AG, Turnbull C, et al. The effects of prophylactic iron given in prenatal supplements on iron status and birth outcomes: a randomized controlled trial. Am J Obstet Gynecol 2006;194:512-19.

12. Scholl T0. Iron status during pregnancy: setting the stage for mother and infant. Am J Clin Nutr 2005;81:1218S-22.

13. Casanueva $\mathbf{E}$, Viteri FE. Iron and oxidative stress in pregnancy. J Nutr 2003;133(Suppl 2):1700S-8.

14. Rasmussen K. Is there a causal relationship between iron deficiency or irondeficiency anemia and weight at birth, length of gestation and perinatal mortality? J Nutr 2001;131(Suppl 2):590S-601.

15. Álvarez-Dardet C, Alonso J, Domingo A, et al. La Medición de la Clase Social en Ciencias de la Salud, Informe de un Grupo de Trabajo de la Sociedad Española de Epidemiología (In Spanish). [The measurement of social class in health sciences. Report from a working group of the Spanish Society of Epidemiology].Madrid: SG Editores, 1995.

16. Townsend P, Davidson N. Inequalities in health, The Black Report. Hammonsworth: Penguin Books Ltd, 1982.

17. Sun GW, Shook TL, Kay GL. Inappropriate use of bivariable analysis to screen risk factors for use in multivariate analysis. J Clin Epidemiol 1996;49:907-16.

18. Maldonado G, Greenland S. Simulation study of confounder-selection strategies. Am J Epidemiol 1993;138:923-36.

19. Mickey RM, Greenland S. The impact of confounder selection criteria on effect estimation. Am J Epidemiol 1989:129:125-37.

20. Agarwal KN, Agarwal DK, Mishra KP. Impact of anaemia prophylaxis in pregnancy on maternal haemoglobin, serum ferritin \& birth weight. Indian J Med Res 1991;94:277-80.

21. Meier PR, Nickerson HJ, Olson KA, et al. Prevention of iron deficiency anemia in adolescent and adult pregnancies. Clin Med Res 2003;1:29-36.

22. Mitchell EA, Robinson E, Clark PM, et al. Maternal nutritional risk factors for small for gestational age babies in a developed country: a case-control study. Arch Dis Child Fetal Neonatal Ed 2004;89:F431-5.
23. Gulmezoglu $\mathbf{M}$, de Onis M, Villar J.Effectiveness of interventions to prevent or treat impaired fetal growth. Obstet Gynecol Surv 1997;52:139-49.

24. Scholl T0, Hediger ML, Schall Jl, et al. Dietary and serum folate: their influence on the outcome of pregnancy. Am J Clin Nutr 1996:63:520-5.

25. Scholl T0, Johnson WG. Folic acid: influence on the outcome of pregnancy. Am J Clin Nutr 2000;71(Suppl):1295S-303.

26. Tamura T, Goldenberg RL, Johnston KE, et al. Serum concentrations of zinc, folate vitamins $A$ and $E$, and proteins, and their relationships to pregnancy outcome. Acta Obstet Gynecol Scand Supp/ 1997;165:63-70.

27. Rolschau J, Kristoffersen K, Ulrich M, et al. The influence of folic acid supplement on the outcome of pregnancies in the county of Funen in Denmark. Part I. Eur J Obstet Gynecol Reprod Biol 1999;87:105-10.

28. Christian $\mathbf{P}$, Khatry SK, Katz J, et al. Effects of alternative maternal micronutrient supplements on low birth weight in rural Nepal: double blind randomised community trial. BMJ 2003:326:571-7.

29. Czeizel AE, Dudas I, Metneki J. Pregnancy outcomes in a randomised controlled trial of periconceptional multivitamin supplementation. Final report. Arch Gynecol Obstet 1994:255:131-9.

30. Kaestel P, Michaelsen KF, Aaby P, et al. Effects of prenatal multimicronutrient supplements on birth weight and perinatal mortality: a randomised, controlled trial in Guinea-Bissau. Eur J Clin Nutr 2005;59:1081-9.

31. Osrin D, Vaidya A, Shrestha Y, et al. Effects of antenatal multiple micronutrient supplementation on birthweight and gestational duration in Nepal: double blind, randomised controlled trial. Lancet 2005:365:955-62.

32. Friis $\mathbf{H}$, Gomo $\mathrm{E}$, Nyazema N, et al. Effect of multimicronutrient supplementation on gestational length and birth size: a randomized, placebo-controlled, double-blind effectiveness trial in Zimbabwe. Am J Clin Nutr 2004;80:178-84.

33. Ramakrishnan U, Gonzalez-Cossio T, Neufeld LM, et al. Multiple micronutrient supplementation during pregnancy does not lead to greater infant birth size than does iron-only supplementation: a randomized controlled trial in a semirural community in Mexico. Am J Clin Nutr 2003;77:720-5.

34. Haider BA, Bhutta ZA Multiple-micronutrient supplementation for women during pregnancy. Cochrane Database Syst Rev 2006;4:CD004905.

35. Allen LH. Biological mechanisms that might underlie iron's effects on fetal growth and preterm birth. J Nutr 2001;131(Suppl 2):581S-9.

\section{Access a vast information database with Toll-Free linking}

"Toll-free" linking gives you immediate access to the full text of many of the cited articles in a paper's reference list-FOR FREE. With the support of HighWire's vast journal catalogue, a huge reference library is now open to you. If HighWire hosts the journal, you can view the full text of the referenced article, completely free of charge by following the Free Full Text links in the references. 